\title{
CONTORNOS DO NOVO DIREITO AUTORAL
}

\section{Felipe dos Reis Barroso}

Mestre em Administração (DePaul University, EUA).

Professor do curdo de Direito da FA7.

felipe.barroso@uol.com.br

Giovanna Lima Santiago Carneiro

Advogada. Graduada em Direito pela FA7.

giovanna2804@yahoo.com.br

Sumário: Introdução. 1. Os direitos autorais. 2. A lei n 9.610/1998 e o projeto de lei. Considerações finais.

Resumo: Os desafios impostos pela tecnologia digital ao direito do autor têm gerado discussões e tentativas de aprimoramento da legislação por diversos setores da sociedade. No presente artigo, analisam-se brevemente propostas feitas pelo Ministério da Cultura para a consolidação de projeto de lei, buscando tentar conciliar e resguardar interesses dos autores e da sociedade.

Palavras-chave: Direito autoral. Obra intelectual. Internet.

\section{INTRODUÇÃO}

O direito de autor, ramo do direito privado, tem como principal objetivo proteger os mais diversos tipos de obras do espírito, como as artísticas e científicas.

Essa proteção dá-se principalmente através da regulamentação da utilização, reprodução, publicação, distribuição e tradução de tais obras, além de outros cuidados com o direito do autor sobre sua própria criação.

Primeiramente, interessante é o estabelecimento de um marco inicial, a partir do qual surgiu a preocupação com os direitos autorais.

A maior parte da doutrina aponta a invenção da máquina de imprensa como o principal acontecimento impulsionador da regulação dos direitos autorais. Porém, mais do que a máquina de imprensa em si, a possibilidade de se multiplicar os escritos foi o fator preponderante. (Abrão, 2008)

Dessa forma, com a evolução dos meios de comunicação surgiu a necessidade de proteger os direitos dos autores, o que foi feito, em primeiro lugar, através da Convenção de Berna, de 1886. Já no Brasil, isso ocorreu um pouco mais tarde, com a Lei 496 de 1898. 


\section{Os Direitos Autorais}

O surgimento da preocupação com os direitos dos autores é relativamente recente no mundo. No Brasil, no tocante à normatização do tema, vale chamar atenção para a lei federal no 5.988/1973, que veio solucionar controvérsias antes existentes em virtude da falta de um diploma que tratasse exclusivamente sobre direitos autorais.

Posteriormente, tal lei foi revogada pela lei $\mathrm{n}^{\circ}$ 9.610/1998 (LA), ainda em vigor. Além da lei específica, os direitos de autor também estão albergados pela Constituição Federal de 1988, especialmente em seu artigo $5^{\circ}$, inciso XXVII, que diz: "aos autores pertence o direito exclusivo de utilização, publicação ou reprodução de suas obras, transmissível aos herdeiros pelo tempo que a lei fixar".

Porém, antes de tratar especificamente dos pontos relevantes da referida lei, vale o destaque a certos aspectos do direito autoral em si. Primeiramente, faz-se importante definir alguns conceitos e princípios que regulam a matéria.

De acordo com Bittar (1999, p. 27): "O sujeito dos direitos autorais é o criador da obra, como titular originário." Ou ainda como disciplina a própria lei 9.610/98, em seu artigo 11: "Autor é a pessoa física criadora de obra literária, artística ou científica."

Já com relação às obras abrangidas pelo direito de autor, ensina Bittar que:

[.... ] se acham compreendidas no contexto do Direito de Autor as obras de caráter estético, ou seja, destinadas à sensibilização ou à transmissão de conhecimentos. São as obras de literatura, de artes e de ciência, enquadrando-se nesse conceito as criações que, por natureza, se revistam dos caracteres próprios em cada campo. (1999, p. 27)

A lei 9.610/98, em seu artigo $7^{\circ}$, diz que: "São obras intelectuais protegidas as criações do espírito, expressas por qualquer meio ou fixadas em qualquer suporte, tangível ou intangível, conhecido ou que se invente no futuro [....]". Ao que se segue um rol exemplificativo de meios e veículos de comunicação em que os autores dos mais diversos tipos de obras podem divulgar suas criações, tais como: obras literárias, científicas, fotográficas, de desenho e muitas outras.

Esclarecidos esses primeiros conceitos, necessário se faz ainda destacar alguns princípios norteadores da matéria. Bittar aponta como um dos postulados centrais o da exclusividade para a exploração da obra, do qual nascem os direitos do autor em relação à proteção da obra. O principal aspecto é o da exploração econômica da obra, como explica o referido autor: 
Com o princípio da exclusividade para a exploração da obra, institui-se a favor do autor monopólio para a utilização econômica, que lhe possibilita usar, gozar, autorizar o uso e transmitir por sucessão os direitos sobre sua criação. (1999, p. 22)

Vale também tratar do princípio da especialidade da matéria, considerando que direito de autor, como um ramo do direito privado, tem suas próprias regras e conteúdo exclusivo.

Porém, no âmbito dos direitos autorais, por ser matéria bastante complexa, percebem-se dúvidas e discussões. Destaque-se, por exemplo, o conflito existente entre direitos individuais e difusos nesta seara. Como se pode imaginar, os direitos do autor sobre sua obra não são absolutos. $\mathrm{O}$ legislador vislumbrou hipóteses em que este direito deve ser limitado em prol de um ganho maior de toda a sociedade. Tais hipóteses referem-se a obras intelectuais que possam trazer conhecimento e informação, como os livros, músicas, obras de artes plásticas:

Essas limitações aos direitos de propriedade intelectual são exceções ao princípio da autorização prévia ao uso público desses direitos por parte de terceiros, recorrência da exclusividade erga omnes. Em todos os casos as limitações estão a atender outros direitos e garantias fundamentais, como o direito à informação ou o direito ao bem-estar social [....] (Abrão, 2008, p. 183)

Vê-se que tal direito envolve tanto interesses de ordem pública, como nos casos de difusão de obras, como interesses de ordem privada, pois visa a proteger o direito do próprio autor. Este, por sua vez, costuma ser subdividido em direitos morais e patrimoniais, assim definidos:

[....] temos acentuado que o aspecto moral é a expressão do espírito criador da pessoa, como emanação da personalidade do homem na condição de autor de obra intelectual estética. Já o elemento patrimonial consubstancia-se na retribuição econômica da produção intelectual, ou seja, na participação do autor nos proventos que da obra de engenho possam advir, em sua comunicação pública. (Bittar, 1999, p. 33)

Ainda de acordo com Bittar, são características do direito moral do autor: a perpetuidade, imprescritibilidade, inalienabilidade e irrenunciabilidade. Considerado direito da personalidade, Bittar (2008, p. 142) chama ainda atenção para o "elo espiritual entre o autor e sua concepção intelectual [....]"

Com relação ao direito patrimonial do autor, a partir do qual o criador de uma obra pode explorar economicamente seus frutos, este pode ser considerado um direito de propriedade, neste caso, propriedade imaterial. 
Percebe-se que o direito de autor possui múltiplas facetas, uma vez que existem diversas teorias que tentam definir sua natureza jurídica, tornando o tema bastante complexo e, por isso, alvo de inúmeras discussões.

Nessa esteira, destaque-se que o Código Civil de 2002 inovou em relação ao diploma anterior, deixando de incluir o direito de autor entre os direitos de propriedade para delegar a lei especial, qual seja a lei no 9.610/98. (Monteiro, 2011)

Após esses breves esclarecimentos, passa-se à análise e comparação entre a Lei de Direitos Autorais e o projeto de lei que pretende modificá-la em alguns pontos.

\section{A Lei No 9.610/1998 E O Projeto de Lei}

Nesse tópico serão analisados os principais artigos da Lei ${ }^{\circ} 9.610$ que foram revisados pelo projeto de lei, a fim de se verificar o que efetivamente se pretende mudar em relação aos direitos autorais.

Antes, porém, cumpre fazer uma brevíssima análise da exposição de motivos do dito projeto de lei para entendermos quais as deficiências do atual ordenamento jurídico no que diz respeito ao tema.

Primeiramente, é apontado conflito de ordem constitucional, uma vez que há um desequilíbrio entre o direito do autor de ter sua obra protegida e o direito fundamental de toda a sociedade de ter acesso ao conhecimento e à cultura. Tais direitos estão resguardados, respectivamente, pelos incisos XXVII e XIV do artigo $5^{\circ}$ da Constituição Federal.

Segundo a exposição de motivos, a norma atual impõe limites a tais direitos:

No entanto, a Lei 9610/98 apresenta uma série de obstáculos ao exercício desses direitos, como a impossibilidade de realização de cópia integral de obra sem autorização prévia, de reprodução de obras para a preservação e restauração, de reprodução de obras direcionadas aos portadores de deficiência física, ou mesmo em alguns casos de atividades de ensino. (Minc, online)

Em segundo lugar, o desequilíbrio na relação entre os autores e os investidores é apontado como um dos motivos para a modificação da atual lei. Embora seja reconhecida a necessidade de uma intermediação de empresas investidoras no sentido da divulgação cultural, há uma resistência quanto à forma como se dá a relação entre os criadores e tais empresas.

Isso porque se verifica a necessidade de valorizar mais a posição do criador, a fim de que este possa se relacionar com as referidas empresas de forma mais igualitária. Assim, vale observar a passagem a seguir: 
De fato, apesar de grande produtor de conteúdos protegidos, os autores brasileiros, titulares originários de direitos no campo da música e do audiovisual, por exemplo, são obrigados a lidar com intermediários que são, em sua absoluta maioria, representantes de multinacionais com sede em outros países. (Minc, online)

O objetivo, no que diz respeito a esse ponto, é fazer com que as riquezas produzidas por autores brasileiros permaneçam dentro do país, e não seja apropriada, em sua maior parte, pelas multinacionais com sede em outros países.

Por último, o projeto de lei defende uma participação efetiva do Estado na proteção dos direitos autorais. A lei $n^{\circ} 9.610$ eliminou a atuação do Estado quando revogou o antigo Conselho Nacional de Direito Autoral, e desde então prevalece a ausência de ações do governo na área dos direitos autorais, situação que surgiu com a ideia de que tais direitos são de ordem privada, não devendo haver intervenção estatal.

Para entender melhor a importância do papel do Estado, apontada como um dos motivos de reforma da lei:

O discurso que defendia a ausência do Estado brasileiro nesse período, com a justificativa de que se trataria de interesses privados, na prática legitimava o resultado das disputas assimétricas entre os atores envolvidos na matéria. Sem qualquer forma de acompanhamento institucional por parte do Estado, as ações de governo existentes na matéria até recentemente se davam mais como resultado das pressões internacionais que o país sofria do que como fruto dos anseios dos criadores e titulares de direitos nacionais, os quais, na ausência de um interlocutor capaz na esfera do Executivo, com frequência sobrecarregaram o poder Judiciário. (Minc, online)

Após essa brevíssima análise da exposição de motivos do projeto de lei e entendendo melhor os objetivos deste, passa-se às principais modificações.

O Ministério da Cultura aponta alguns dispositivos principais da lei que devem ser aperfeiçoados nesta etapa final do processo de reforma, por isso o presente artigo se concentrará nos referidos pontos.

Primeiramente, no título que trata das limitações aos direitos do autor, pode-se observar uma mudança no sentido de ampliar essas limitações, uma vez que abre mais possibilidades de reprodução de obras, como no caso do artigo 48, no qual foram incluídas as obras de artes visuais, reforçando o direito da sociedade de acesso à cultura e ao conhecimento. Referido dispositivo está com a seguinte redação: "Art. 48. As obras de artes visuais e arquitetônicas permanentemente situadas em logradouros públicos podem ser livremente representadas, por qualquer meio ou processo, inclusive fotográfico ou audiovisual." 
Importante citar ainda a modificação do inciso I do artigo 46, que autoriza a reprodução, em uma só cópia, de obra publicada e obtida de maneira legal e desde que para fins não comerciais, autorização que não consta na lei atual.

Outro ponto muito relevante do projeto de lei é o que diz respeito à reprografia das obras literárias, sobre o que tratam os artigos 88-A e 88-B, adicionados ao texto da lei. Vale chamar atenção especificamente para segundo, pois deixa claro que o direito do autor sobre sua obra não é absoluto:

Art. 88-B. O Poder Judiciário poderá autorizar a reprografia de obras literárias sempre que, ao exercer seus direitos patrimoniais, o titular dos direitos de reprodução ou a respectiva associação de gestão coletiva exceda manifestamente os limites impostos pelo seu fim econômico ou social, pela boa-fé ou pelos bons costumes, ou impeça o exercício do direito constitucional à educação.

Tal dispositivo representa também uma limitação ao direito autoral, visto que impede o autor de usar e dispor de sua obra como bem entender. Isso quer dizer que, uma vez criada, a obra desempenha um papel perante toda a sociedade, e nem o próprio autor pode transpor os limites da boa-fé, por exemplo, apenas por ser o criador.

Nessa mesma linha de raciocínio, importante também transcrever a redação do artigo 110-A: "O titular de direito autoral, ou seu mandatário, que, ao exercer seu direito de forma abusiva, praticar infração da ordem econômica sujeitar-se-á, no que couber, às disposições da Lei no 8.884 [....]"

Com relação à participação do Estado no âmbito dos direitos autorais, o projeto de lei pretende a criação de um órgão fiscalizador das entidades arrecadadoras.

Atualmente, o Escritório Central de Arrecadação e Distribuição (ECAD) é a maior entidade arrecadadora do país. Associação civil de natureza privada, atua como substituto processual dos autores associados, arrecadando os valores relativos aos direitos patrimoniais destes, funções descritas no artigo 98 do projeto de lei:

Art. 98. Com o ato de filiação, as associações de gestão coletiva de direitos autorais de que trata o art. 97 tornam-se mandatárias de seus associados para a prática de todos os atos necessários à defesa judicial ou extrajudicial de seus direitos autorais, bem como para o exercício da atividade de cobrança desses direitos.

O objetivo, portanto, do projeto de lei parece-nos ser criar um órgão do governo cuja função seria fiscalizar esse tipo de associação arrecadadora, tornando a participação do Estado mais efetiva na proteção dos direitos autorais, como já acontece em diversos países. 
Dessa forma, o projeto de lei torna condição necessária à existência da entidade arrecadadora seu registro no Ministério da Cultura, o que, por sua vez, está condicionado ao atendimento de uma série de requisitos, elencados no caput do artigo 98-A: "O exercício da atividade de cobrança de que trata o art. 98 dependerá de registro prévio no Ministério da Cultura, conforme disposto em regulamento [....]"

Entre os requisitos, vale o destaque para a demonstração de uma administração eficaz em que sejam seus associados representados de forma transparente, bem como a apresentação de diversos documentos, como cadastro das obras e seus titulares, além de contratos, convênios, atas das assembleias etc.

Outro ponto relevante a ser discutido nesse processo de reforma é, sem dúvida, a questão dos conteúdos publicados na internet. Com a evolução da tecnologia, a divulgação de informações é feita de maneira cada vez mais rápida, exigindo adequação do ordenamento jurídico à nova realidade.

Essas relações estabelecidas através da internet demandam regulamentação, o que está sendo buscado pela reforma da lei de direitos autorais. Observe-se o que prevê o projeto:

Art. 105-A. Os responsáveis pela hospedagem de conteúdos na Internet poderão ser responsabilizados solidariamente, nos termos do Artigo 105, por danos decorrentes da colocação à disposição do público de obras e fonogramas por terceiros, sem autorização de seus titulares, se notificados pelo titular ofendido e não tomarem as providências para, no âmbito do seu serviço e dentro de prazo razoável, tornar indisponível o conteúdo apontado como infringente.

Além disso, dispõe ainda o projeto de lei que os responsáveis pela hospedagem de conteúdos na internet deverão disponibilizar um espaço para o recebimento de notificações que tenham como objetivo, principalmente, a retirada de conteúdo considerado infringente. As próprias notificações devem atender a alguns requisitos, como conter a identificação do notificante e do conteúdo que deverá ser removido, de acordo com os parágrafos $1^{\circ}$ e $2^{\circ}$ do artigo 105-A.

Essas foram algumas das propostas de mudança apresentadas pelo projeto de lei, submetidas à apreciação da sociedade, para que seus membros contribuíssem com ideias e sugestões.

Os dispositivos acima apresentados estão entre os que foram detectados pelo Minc como objetos de aperfeiçoamento nessa fase final da reforma.

\section{Considerações Finais}

A evolução da tecnologia, dos meios de comunicação e da própria sociedade fez surgir inúmeras discussões em torno da questão dos direitos autorais. 
Sentiu-se a necessidade de adequar a legislação à situação atual, protegendo os direitos dos autores, porém não se esquecendo de resguardar o direito fundamental de toda a sociedade de ter acesso à informação e à cultura.

Para dar mais equilíbrio à relação entre esses direitos conflitantes, a reforma busca também uma maior participação do Estado na esfera dos direitos autorais, o que pode dar mais segurança aos criadores e mais credibilidade às entidades arrecadadoras.

Com isso, espera-se que os autores brasileiros sejam mais valorizados e tenham seus direitos morais e patrimoniais garantidos, sem que isso cerceie o direito ao acesso ao conhecimento, à informação e à cultura.

\section{REFERÊNCIAS}

ABRÃO, Eliane Y. O interesse público e o privado na propriedade intelectual. Revista de Direito do Trabalho, $n^{\circ}$ 131. São Paulo: Revista dos Tribunais, 2008. BITTAR, Carlos Alberto. Contornos atuais do direito do autor. São Paulo: Revista dos Tribunais, 1999.

BITTAR, Carlos Alberto. Os direitos da personalidade. Rio de Janeiro: Forense Universitária, 2008.

BRASIL. Lei $\mathbf{n}^{0} 9.610$ de 19 de Fevereiro de 1998. Disponível em: <www. presidencia.gov.br>

MOTEIRO, Washington de Barros; MALUF, Carlos Alberto Dabus. Curso de Direito Civil. São Paulo: Saraiva, 2011.

PELLEGRINI, Luiz Fernando Gama. Direitos Autorais. Direitos morais dos sucessores. Obra caída em domínio público. Rio de Janeiro: Forense, 2009.

SOUZA, Carlos Fernando Mathias de. Direito Autoral. Brasília: Brasília Jurídica, 1998.

\section{ON NEW AUTHOR'S RIGHTS}

Abstract: Digital technology has been imposing important challenges on legal aspects of author's rights in Brazil. This article focuses briefly on the propositions made by the Ministry of Culture, envisaging the consolidation of a project of law that attempts to conciliate interests of authors and society.

Keywords: Author's rights. Intelectual work. Internet.

Data de recebimento: set/2010 - Data de aprovação: nov/2010 